\title{
DISCURSO DE GRADUACIÓN DE LA OCTAVA PROMOCIÓN DE MÉDICOS FUNDACIÓN UNIVERSITARIA DE CIENCIAS DE LA SALUD
}

Dr. Jorge Gómez Cusnir*

Junio 15 de 2007

He tenido el honor y la fortuna de presidir la celebración de acontecimientos muy importantes en la historia de la Sociedad de Cirugía de Bogotá, Hospital de San José y de la Fundación Universitaria de Ciencias de la Salud, como la celebración del centenario de la primera el 22 de julio de 2002. Vamos a cumplir el próximo mes 105 años de historia y compromiso con el progreso y desarrollo de las ciencias de la salud de nuestro país. Hace escasos tres años me dirigía en la ceremonia de graduación de la primera promoción de médicos de nuestra propia facultad, cumpliendo así con uno de los grandes anhelos de nuestros fundadores, el de educar hombres de bien en el arte de Hipócrates, cuya sólida formación fuera el reflejo de la escuela de esta casa del saber médico, el Hospital de San José y la Fundación Universitaria de Ciencias de la Salud. Ustedes son la octava promoción de egresados de nuestra propia institución docente y llevan la impronta indeleble de nuestra escuela medicoquirúrgica y la enorme responsabilidad de perpetuarla.

Sin duda alguna la centenaria tradición docente y una escuela de reconocida trayectoria y calidad académica convirtieron a nuestra institución hospitalaria en estos algo más de 82 años de existencia, en un centro docente asistencial en donde la academia siempre ha permanecido estrechamente ligada a la actividad médica y demás ciencias de la salud. Hemos pasado de cientos a miles de profesionales ilustres en

* Presidente Sociedad de Cirugía de Bogotá, Hospital de San José y Consejo Superior de la Fundación Universitaria de Ciencias de la Salud. distintos campos de la medicina y las ciencias de la salud que acudimos a estas aulas, haciendo enormes aportes al desarrollo e historia médica colombianas y conformamos con ustedes queridos graduandos, un gran grupo de egresados que ocupan o han ocupado lugares de privilegio a lo largo y ancho de la geografía colombiana y algunos han trascendido las fronteras patrias.

Por esta casa del saber han pasado los estudiantes de las principales facultades de medicina como la Universidad Nacional y la Universidad Javeriana. $\mathrm{Al}$ retirarse esta última, se firmó el convenio entre la Sociedad de Cirugía de Bogotá y el Colegio Mayor de Nuestra Señora del Rosario, iniciando actividades la facultad de medicina en 1965 hasta el segundo semestre del 2000 , por treinta y cinco años. Durante algún tiempo recibimos alumnos de la Universidad El Bosque y a partir de 1999 los estudiantes de nuestra facultad que hoy culminan sus estudios de pregrado.

Es indudable que para que hubiera sido posible esta pequeña reseña histórica que he querido trasmitirles el día de hoy, han existido personajes íntimamente ligados al desarrollo de nuestras instituciones y de sus actividades asistenciales y docentes, y que hoy recordamos con admiración, gratitud y orgullo, ya que muchos hoy desafortunadamente no nos acompañan, pero estoy seguro que sus enseñanzas y su espíritu se perpetúa en cada uno de los que hemos tenido la fortuna de contarnos entre sus alumnos y 
compañeros de trabajo. Hoy quisiera referirme y rendir un tributo póstumo a una de las personas más queridas y representativas tanto de la Sociedad de Cirugía de Bogotá, Hospital de San José, como de la Fundación Universitaria de Ciencias de la Salud y que desafortunadamente no nos acompaña como hubiera sido su deseo. Estoy seguro que gracias a sus actividades primero como decano de la facultad de medicina y luego como nuestro vicerrector académico, dio ejemplo de compromiso, pundonor, responsabilidad y templanza hasta los últimos momentos de su vida. El profesor doctor Alfonso Tribín Ferro para quien solicito un caluroso aplauso y de pie oremos en un minuto de silencio por su eterno descanso. En todos estos años han existido otros tantos a quienes debemos sus enseñanzas y ejemplo, sería imposible siquiera en este breve tiempo mencionarlos a todos y no pretendo hacer un panegírico en particular, pues cada uno de los que han pertenecido en estos 105 años de historia, han hecho grandes aportes a nuestras instituciones.

Desde 1994 nuestra institución docente se ha convertido en Fundación Universitaria de Ciencias de la Salud y al culminar el convenio con la Universidad del Rosario en el segundo semestre del año 2000, se inicia una nueva etapa de desarrollo y progreso de nuestras instituciones. En 1996, la asamblea de la Sociedad de Cirugía de Bogotá aceptó la idea de su presidente el doctor Darío Cadena Rey, hoy nuestro vicerrector de proyectos especiales de adelantar los trámites para la creación de una nueva facultad de medicina que tendría como sede el Hospital de San José y así cumplir con las exigencias de ley para poder conservar los programas de postgrado existentes en ese momento.

Con la decidida colaboración del doctor Eduardo Palacios Sánchez, rector en ese entonces de la FUCS, del vicepresidente doctor Luís Carlos Taborda y el doctor Roberto Jaramillo como jefe de postgrados, se adelantaron los trámites ante el ICFES y finalmente se obtuvo el registro del programa el $16 \mathrm{de}$ diciembre de 1997.
Con el profesor Roberto Jaramillo como su primer decano y luego de conformar un eximio equipo de docentes, el primer grupo de alumnos, 40 en total, inician actividades el 5 de marzo de 1998 y de ellos 19 supervivientes conformaron la primera promoción de egresados.

Desde entonces el equipo directivo ha tenido algunos cambios y la estructura académica, financiera y administrativa que hoy conforma la comunidad universitaria nos ha permitido alcanzar importantes logros para nuestra institución educativa. Con enorme tradición pero muy joven en años, hoy podemos decirles que la Fundación Universitaria de Ciencias de la Salud en estos últimos años ha conseguido el registro calificado de todos sus programas de pregrado, la acreditación de alta calidad para su programa de enfermería, el registro calificado de 30 de sus 32 programas de postgrado medicoquirúrgicos y se continúa trabajando en la acreditación de calidad de nuestra facultad de medicina y de los otros programas académicos en búsqueda de la acreditación institucional en los próximos años, como política impartida desde nuestro Consejo Superior. Es oportuno hacerle el reconocimiento a toda la comunidad universitaria, al grupo directivo, al cuerpo docente y a todos los estudiantes que son nuestra razón de ser, por todas las metas alcanzadas en tan poco tiempo, lo que nos motiva para continuar con nuestro empeño de convertirnos en los próximos años en una de las mejores universidades del país, sin olvidar nuestras fortalezas en el campo de las ciencias de la salud; para todos un merecido aplauso.

El camino recorrido no ha sido fácil y ustedes queridos graduandos han sido testigos de lujo de los enormes esfuerzos realizados por nuestras instituciones por ofrecerles las mejores condiciones de aprendizaje que hoy existen en nuestro país en las facultades de medicina y gracias a ese titánico esfuerzo se suma a nuestro querido Hospital de San José, el Hospital Infantil Universitario de San José, antiguo hospital Lorencita Villegas de Santos como nuestro segundo hospital universitario propio, como centro de prácticas de pre y postgrado para nuestras distintas facultades. 
Hoy ya se han entregado al servicio más de 16.000 metros cuadrados, la gran central de urgencias, 53 camas de hospitalización, consulta externa, apoyo en imágenes diagnósticas, TAC multicortes, hemodinamia, laboratorio clínico, entre otros servicios y en aproximadamente un mes y medio se darán al servicio 8.600 metros cuadrados más para las salas de cirugía, salas de parto, 53 camas de cuidado crítico de adultos, neonatal y pediátrico y cuidados intermedios. De manera simultánea se abrirán 50 camas adicionales de hospitalización. Hemos construido un grupo empresarial con el desarrollo de nuestras instituciones, implementando cambios en la estructura organizacional y administración de la universidad y el hospital, que han permitido la actualización tecnológica, de infraestructura física y tratar de mejorar las condiciones financieras, que permitieran los propósitos de darle a nuestras instituciones el sitial de honor que se merecen en el ámbito nacional. Hoy con orgullo podemos decir que son muchos los logros alcanzados por un gran equipo que conforman la gran familia de la Fundación Universitaria de Ciencias de la Salud y la Sociedad de Cirugía de Bogotá, Hospital de San José.

La Fundación Universitaria de Ciencias de la Salud, cuenta hoy con dos hospitales propios de cuarto nivel de complejidad, en plena operación como su principal ventaja competitiva, con una escuela de reconocido prestigio y que puede ofrecer a este nuevo grupo de egresados 32 programas de especialización en áreas médicas y quirúrgicas para complementar su formación profesional.

Queridos graduandos, hace seis años cuando tomaron la decisión de estudiar en esta casa del saber, les decíamos que ustedes conformaban un grupo de privilegiados al poderse contar entre los pocos que podían acceder a formarse en esta bella profesión, cada vez más afectada por los cambios originados desde la implementación de la ley 100 de 1993, pero que también brinda la oportunidad de aportar al mejoramiento de la calidad de vida de nuestros compatriotas a aquellos mejor preparados, y es allí en donde podemos hablar de privilegios. Ustedes han recibido una formación integral en una institución de salud centenaria, con la vejez de sus años al servicio de la salud de la comunidad, pero con el espíritu siempre joven de la innovación y el deseo de su permanente actualización académica y tecnológica, que cuenta con un grupo de docentes de gran experiencia y trayectoria, que han construido una escuela de la cual hoy ustedes hacen parte y que tendrán la enorme responsabilidad de continuar el día de mañana.

Tienen como sus antecesores la enorme responsabilidad de llevar y dejar siempre en lo alto el nombre de la institución que hoy les confiere su título de médicos; la responsabilidad de continuar el legado recibido de sus profesores, que han dado todo de sí para que ustedes sean los grandes médicos de nuestro país y quienes perpetúen la escuela y tradición de la Sociedad de Cirugía de Bogotá, Hospital de San José y el buen nombre de la Fundación Universitaria de Ciencias de la Salud.

De hoy en adelante asumen el reto de demostrar que no se equivocaron al escoger esta institución como su Alma Mater, están obligados a esgrimir los principios, los valores y los conocimientos que han dejado como impronta sus profesores, a quienes deben gratitud, admiración y respeto. Deben continuar con tesón y fortaleza, abriendo el camino para los que vienen, en lo laboral, lo académico, lo administrativo, en la investigación o en lo asistencial. Esta ceremonia siempre estará cargada para ustedes de recuerdos, gratos y amargos, de ensayo y error, pero al fin del camino, nadie les podrá quitar el que son la octava promoción de médicos de la FUCS en el año 2007.

Queridos graduandos les deseo el mejor de los éxitos en esta nueva etapa que hoy inician, a sus padres y familiares quienes han hecho enormes sacrificios para que ustedes obtengan el diploma que hoy se les otorga. Reciban de toda la comunidad universitaria nuestra sincera felicitación y un merecido aplauso.

Muchas gracias. 